\title{
Regulatory approval time for hormonal contraception in Canada, the United States and the United Kingdom, 2000-2015: a retrospective data analysis
}

\author{
Christine Troskie, Judith A. Soon RPh PhD, Arianne Y. Albert PhD, Wendy V. Norman MD MHSc
}

Abstract

Background: Access to a wide range of contraceptive methods improves prevention of unintended pregnancy by ensuring the best method fit for each individual. We compared approval times of new hormonal contraceptives by Health Canada, the US Food and Drug Administration (FDA), and the UK Medicines and Healthcare Products Regulatory Agency (MHRA).

Methods: We obtained dates of applications to Health Canada, the FDA and the MHRA for contraceptive methods approved from January 2000 to January 2015. We used public data sources and direct correspondence, and excluded generic versions of previously approved drugs. The primary outcome of interest was median time to approval for novel hormonal contraceptives. Secondary outcomes included the median time to approval for all hormonal contraceptives and the number of approved hormonal contraceptives comparing countries studied, as well as the median time for approval of novel compared with nonnovel hormonal contraceptives within each country.

Results: During this period 16 contraceptives were approved in Canada, 26 in the US and 14 in the UK. Applications for novel contraceptives were initiated later in Canada, and time to approval was longer in Canada than in the US $(p=0.03)$. The median time to approval for all contraceptives in Canada was 529.5 (interquartile range [IQR] 420.8 to 784.0) days, compared with 396.0 (IQR 308.0 to 594.5 ) days in the US and 341.0 (IQR 244.8 to 512.2) days in the UK. No subdermal implant contraceptives are approved in Canada.

Interpretation: Canadian women wait longer for novel contraceptive methods and have fewer options. Canada could improve population health by addressing the regulatory barriers associated with the unmet need for contraception. Facilitation for approval of a contraceptive implant, and improvement to prolonged novel drug approval times, could support Canadians to plan and space their pregnancies.

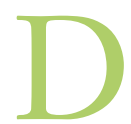

ifferences in availability of hormonal contraceptives between Canada and other Western countries was shown in the 1990s, but recent evaluations are lacking. ${ }^{1}$ Azzarello and Collins ${ }^{1}$ found that, before the year 2000, Canadian women had access to fewer hormonal contraceptives than women in the United States and the United Kingdom. Downing and colleagues ${ }^{2}$ noted that the overall drugapproval process through Health Canada, considering all classes of drugs, required more time than similar approvals in the US and the UK. ${ }^{2}$ Researchers have compared overall access to new drugs in Canada with access in the US and the European Union (EU). The delay in submission to national drug regulatory agencies by pharmaceutical companies, when compared between Health Canada, the US Food and Drug Administration (FDA) and the European Medicines Agency (EMA), was greater than the delay due to the approval process, ${ }^{3}$ compounding the delayed access to pharmaceuticals for Canadians.
In $2005,31 \%$ of Canadian women completing their reproductive years had experienced at least 1 abortion. ${ }^{4}$ Because unintended pregnancy is common, women benefit when

Competing interests: Christine Troskie received a scholarship from Wendy Norman's Applied Public Health Chair grant. Wendy Norman and Judith Soon conducted an investigator-initiated randomized controlled trial in 2009, to which Bayer Canada donated contraceptive devices. After submission of the initial manuscript, Bayer Canada provided an unrestricted training grant for the support of a postdoctoral fellow trainee within the research program of Wendy Norman. Wendy Norman received grants from the Canadian Institutes of Health Research and the Public Health Agency of Canada as Applied Public Health Chair, and is supported as a Scholar of the Michael Smith Foundation for Health Research. No other competing interests were declared.

This article has been peer reviewed.

Correspondence to: Wendy Norman, wendy.norman @ubc.ca CMAJ Open 2016. DOI:10.9778/cmajo.20160017 
timely access to suitable contraceptive methods is available. ${ }^{4-7}$ Hormonal contraceptives are convenient and effective resources that allow women to plan and space pregnancies. ${ }^{8-18}$ Long-acting reversible contraceptives (LARC), including intrauterine devices and subdermal implants, are the most effective nonpermanent methods to prevent unintended pregnancy and thus to support women in timing and spacing their pregnancies. ${ }^{11,15-18}$ Currently, hormonal contraceptives are available via several routes of administration: oral, vaginal, transdermal, injection, dermal patch, intrauterine or subdermal implants. ${ }^{19}$ Hormonal contraceptives are available with varying amounts of estrogen, and types and amounts of progestin. Having a range of available contraceptive choices, including variations in route of administration and hormonal mix and dosage, allows women to select methods that best fit their individual requirements. ${ }^{8,20,21}$ Contraceptives that more closely align with individual needs are more likely to be used. ${ }^{9,10,22}$ In particular, "set and forget" LARC intrauterine and implant methods have been exceptionally effective in reducing unintended pregnancies. ${ }^{11,15-18}$ The timely approval of a full range of contraceptive methods is important to assist women and their families in meeting their reproductive goals.

We explored the regulatory approval times of new hormonal contraceptives by Health Canada since the year 2000, and compared these to approval times of the FDA in the US and the EMA in Europe. However, as most European countries individually approve contraceptives, the EMA, a common agency for many European countries, has approved very few contraceptives. Thus we chose a single European country as a comparator, using submission and approval data of the Medicines and Healthcare Products Regulatory Agency (MHRA) of the UK. In this way we aimed to understand the relative timelines for hormonal contraceptive approval in Canada, the US and the UK.

\section{Methods}

\section{Setting and design}

We collected data for this observational study from Health Canada, the FDA and the MHRA. We included all available data related to any application to each of these agencies for any hormonal contraceptive medication approved from January 2000 to January 2015. We included all routes of delivery for hormonal contraception: oral tablets, dermal patches, intravaginal rings, intrauterine delivery systems and subdermal implants. We excluded generic versions of previously approved drugs. Two specific products were approved after January 2000 in Canada but received prior approval elsewhere. For comparison purposes, we included UK and US data from 1998 on the submission and approval times of these 2 products.

\section{Data sources}

We used Health Canada's Drug Product Database, ${ }^{19}$ Notice of Compliance Database, ${ }^{23}$ and Drugs and Health Products Patent Register ${ }^{24}$ to determine application and approval dates for contraceptives in Canada. We used Health Canada's Health Products and Food Branch performance reports for
2004, 2005 and 2006/07,25-27 and the Drug Submission Performance Annual Reports for Therapeutic Products ${ }^{28,29}$ to cross-check application and approval dates when possible. Correspondence with the Health Canada Office of Submissions and Intellectual Property provided approval dates for applications not publicly available from Health Canada sources. We were not able to access any information related to applications for contraceptives that may have been submitted to Health Canada, the FDA or MHRA but not approved.

For contraceptives approved in the US, we accessed dates through the FDA Approved Drug Products Database. ${ }^{30}$ This database was incomplete for some available contraceptives, and thus we corresponded with the FDA Division of Drug Information to complete the data.

Owing to the different paths to drug approval in the EU, we searched several databases for contraceptive availability in Europe. Few contraceptives were approved through the EMA, ${ }^{31}$ and most contraceptives were approved through the MHRA. ${ }^{32}$ For contraceptives approved in the UK, in addition to the information supplied directly through the MHRA public website, ${ }^{32}$ additional information was obtained in Drug Information: A Guide to Current Resources ${ }^{33}$ on the drugapproval process in the UK. On the MHRA website, we retrieved patient information leaflets and summaries of product characteristics, for contraceptives available in the UK, ${ }^{34}$ as well as final approval dates. We used the MHRA public assessment reports ${ }^{35}$ where possible, and corresponded with the Information Management Division of MHRA for contraceptive application and approval dates not available on the MHRA website.

We found additional and confirmatory information for Canada, the US and the UK through the International Planned Parenthood Federation's Directory of Hormonal Contraceptives. ${ }^{36} \mathrm{We}$ used published literature ${ }^{1}$ to confirm contraceptives approved before 2002. The Drug Information Handbook provided a complete list of contraceptives available in Canada and the US. ${ }^{37}$

\section{Outcomes}

As the condition of interest is the availability for women in each country of a range of choices for contraception, our primary outcome of interest was median time to approval for novel hormonal contraceptives (i.e., those that increase the range of choices). Secondary outcomes included the median time to approval for all hormonal contraceptives and the number of approved hormonal contraceptives comparing countries studied, as well as the median time for approval of novel compared with nonnovel hormonal contraceptives within each country.

\section{Statistical analysis}

We defined time to approval as the number of days between the date of application submission and approval for each drug for Canada, the US and the UK. We examined the approval times for novel and nonnovel pharmaceuticals together and separately. We defined a hormonal contraceptive as novel when the product involved either a new active ingredient, 
such as a new type of progestin, or a new drug delivery system, such as an intravaginal ring.

We compared the approval times between the countries for these particular drugs using Wilcoxon signed-ranks tests for paired data, for pairwise tests (Canada v. US and Canada v. UK). This accounts for the identity of the drugs and does not treat them as independent data points when submitted to the different countries. We also compared the proportion of drugs submitted to both countries that were submitted for approval first to Canada, versus the US or the UK, using binomial sign tests and comparing to a null hypothesis of $50 \%$. Finally, we compared overall approval times (unpaired) for all drugs among the 3 countries using a Kruskal-Wallis test.

Time to approval was compared for the novel drugs between Canada and the US, and Canada and the UK as above using Wilcoxon signed-rank tests. Similarly, the difference in the time to approval between novel and nonnovel drugs was compared within countries using Wilcoxon rank-sum tests.

\section{Results}

During the study period, 16 drugs or devices were approved in Canada (7 novel, 9 nonnovel), 14 in the UK (7 novel, 7 nonnovel), and 26 in the US ( 8 novel and 18 nonnovel). There were 16 drugs for which we had approval times in Canada and the US, and 9 with approval times in Canada and the UK (Figure 1). Table 1 gives a breakdown of all hormonal contraceptives approved in each of the 3 jurisdictions during the study period and specifies the jurisdiction(s) in which they were approved.

Due to the nonnormality of the data, we report medians, interquartile ranges (IQRs) and ranges for the approval times. Figure 2 shows the approval times for all drugs within each country. There was no significant difference among the countries for overall approval time (Kruskal-Wallis $p=0.06$ ); however, there was a trend for the approval time to be longer in Canada. Median approval times were 529.5 (IQR 420.8 to 784.0, range 293 to 1926) days in Canada, 396.0 (IQR 308.0 to 594.5 , range 180 to 1263 ) days in the US and 341.0 (IQR 244.8 to 512.2 , range 58 to 800 ) days in the UK. There were 2 large outliers in Canada: ethinyl estradiol with drospirenone 30/3000 $\mu \mathrm{g}$ (e.g., Yasmin) had an approval time of 1926 days, and ethinyl estradiol with desogestrel (e.g., Linessa) had an approval time of 1701 days. Further, no subdermal implants have yet been approved in Canada, although 2 types are available in both other jurisdictions.

Of the 16 drugs with approval times in both Canada and the US, there was only 1 (intrauterine progestogen, levonogestrel $52 \mathrm{mg}$, Mirena) submitted in Canada before submission in the US ( $\operatorname{sign}$ test $p<0.001)$. Of the 9 with approval times in Canada and the UK, there were 2 (intravaginal ring, Nuvaring, and ethinyl estradiol with drospirenone $30 / 3000 \mu \mathrm{g}$, Yasmin) that were submitted in Canada before submission in the UK (sign test $p=0.2$ ). There was a trend for the approval time to be longer in Canada than in the US among paired comparisons of the same drug submitted to both, with the median number of additional days of
156 (IQR -35 to 414), but this was not significant (Wilcoxon signed-ranks $p=0.07)$. The difference in approval time between Canada and the UK for paired comparisons of the same drug approved in both settings found Canada required an additional median of 89 (IQR -1 to 414 ) days, which was also not significant (Wilcoxon signed-ranks $p=0.1$ ).

\section{Novel drug analysis}

The median time to approval for novel drugs was 561 (interquartile range [IQR] 529.5 to 742) days in Canada, 365 (IQR 309.5 to 665.8 ) days in the US and 361 (IQR 145 to 496.5 ) days in the UK. The time to approval of the novel drugs approved in both countries was longer for Canada than the US (Wilcoxon signed-ranks $p=0.03$; Table 2). In contrast, there was no significant difference between Canada and the $\mathrm{UK}$ in the time to approval of the novel drugs (Wilcoxon signed-ranks $p=0.2$ ).

There was no significant difference in the approval time when we compared overall approvals for novel versus nonnovel drugs within any of the 3 countries (all $p>0.2$ ).

\section{Interpretation}

From 2000 to 2015, fewer hormonal contraceptives were approved in Canada than in the US, and Canadian regulators required significantly more time for approval of novel contraceptives than US regulators. As of January 2015, no subdermal implants had been approved for use in Canada, although more than 1 type was available in both the US and the UK. Once an application was submitted, Health Canada tended to require $30 \%$ more time to approve contraceptives than the FDA in the US, and nearly 50\% longer than the MHRA in the UK. Health Canada approved fewer hormonal contraceptives than the FDA (16 v. 26).

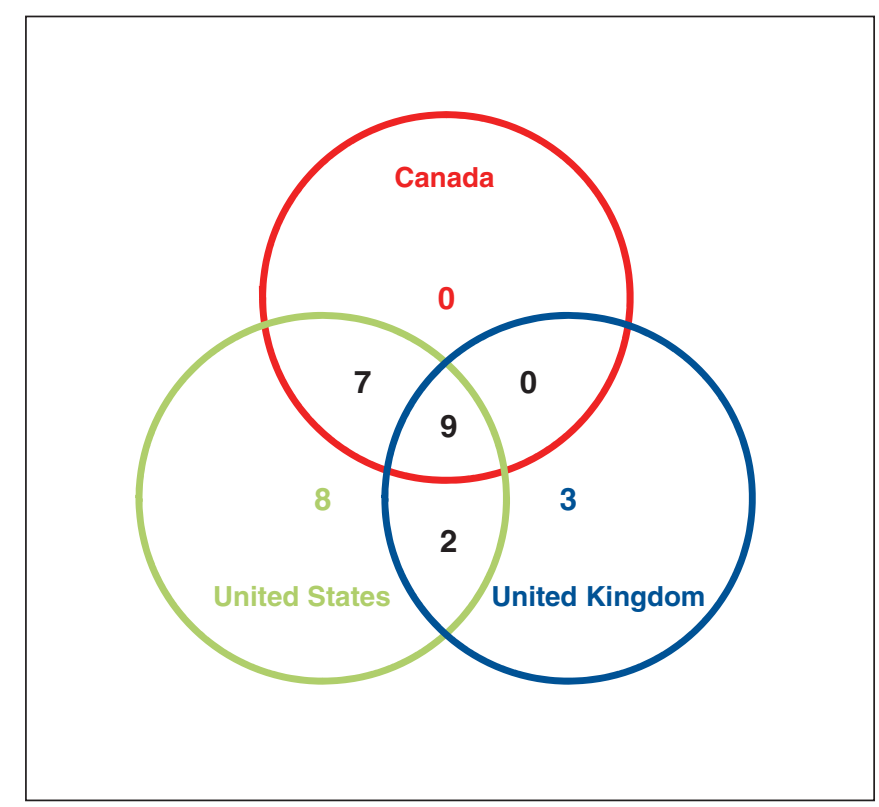

Figure 1: Number of hormonal contraceptives approved in 1, 2 or all 3 jurisdictions, 2000-2015. 
Table 1: Hormonal contraceptives approved by the US Food and Drug Administration, Health Canada, and the UK Medicines and Healthcare Products Regulatory Agency between January 2000 and January 2015

\begin{tabular}{|c|c|c|c|c|c|c|}
\hline \multirow[b]{2}{*}{ Type; common name } & \multirow[b]{2}{*}{ Brand name(s) } & \multirow[b]{2}{*}{ Strength } & \multirow[b]{2}{*}{ Company } & \multicolumn{3}{|c|}{ Approved } \\
\hline & & & & Canada & US & UK \\
\hline \multicolumn{7}{|l|}{ Monophasic } \\
\hline \multirow{4}{*}{$\begin{array}{l}\text { EE with norethindrone } \\
\text { acetate + iron } \\
\text { (norethisterone in the } \\
\text { UK) }\end{array}$} & Lo Loestrin Fe (US) & $10 / 1000 \mu \mathrm{g}+10 \mu \mathrm{g} \mathrm{EE}$ & Warner Chilcott & No & Yes & No \\
\hline & Loestrin $24 \mathrm{Fe}$ (US) & $\begin{array}{l}20 / 1000 \mu \mathrm{g}+75 \mu \mathrm{g} \text { iron }(24 \mathrm{~d} \text { of } \\
\text { hormones) }\end{array}$ & Warner Chilcott & No & Yes & No \\
\hline & Femcon Fe (US) & $35 / 400 \mu \mathrm{g}+$ iron & Warner Chilcott & No & Yes & No \\
\hline & $\begin{array}{l}\text { Minastrin } 24 \text { Fe chewable } \\
\text { (US) }\end{array}$ & $\begin{array}{l}20 / 100 \mu \mathrm{g}+75 \mu \mathrm{g} \text { iron }(24 \mathrm{~d} \text { of } \\
\text { hormones) }\end{array}$ & Warner Chilcott & No & Yes & No \\
\hline $\begin{array}{l}\text { EE with norethindrone } \\
\text { acetate }\end{array}$ & $\begin{array}{l}\text { Lo Loestrin (US), } \\
\text { Lolo (Canada) }\end{array}$ & $10 / 1000 \mu \mathrm{g}+10 \mu \mathrm{g}$ EE & Warner Chilcott & Yes & Yes & No \\
\hline EE with norethindrone & $\begin{array}{l}\text { Generess Fe chewable } \\
\text { (Canada, US) }\end{array}$ & $25 / 800 \mu \mathrm{g}(24 \mathrm{~d})$ & Warner Chilcott & Yes & Yes & No \\
\hline $\begin{array}{l}\text { EE with norethindrone } \\
\text { acetate + iron }\end{array}$ & $\begin{array}{l}\text { Lo Minastrin Fe chewable } \\
\text { (US) }\end{array}$ & $\begin{array}{l}10 / 1000 \mu \mathrm{g}(24 \mathrm{~d})+0.01 \mathrm{EE}(2 \mathrm{~d}) \\
+1 \mathrm{mg} \text { iron }(2 \mathrm{~d})\end{array}$ & Warner Chilcott & No & Yes & No \\
\hline $\begin{array}{l}\text { EE with nomegestrol } \\
\text { acetate }\end{array}$ & Zoely (UK) & $1.5 \mathrm{mg} / 2.5 \mathrm{mg}$ & Teva & No & No & Yes \\
\hline \multirow[t]{4}{*}{ EE with drospirenone } & Yaz (Canada, US, UK) & $20 / 3000 \mu \mathrm{g}(24 \mathrm{~d})$ & Bayer & Yes & Yes & Yes \\
\hline & Yasminelle (UK) & $20 / 3000 \mu \mathrm{g}(21 \mathrm{~d})$ & Bayer & No & No & Yes \\
\hline & Flexyess (UK) & $20 / 3000 \mu \mathrm{g}(24 \mathrm{~d})$ & Bayer & No & No & Yes \\
\hline & Yasmin (Canada, US) & $30 / 3000 \mu \mathrm{g}(21 \mathrm{~d})$ & Bayer & Yes & Yes & Yes \\
\hline \multirow[t]{2}{*}{$\begin{array}{l}\text { EE with drospirenone + } \\
\text { levomefolate calcium }\end{array}$} & $\begin{array}{l}\text { Yaz Plus (Canada), Beyaz } \\
\text { (US) }\end{array}$ & $\begin{array}{l}20 / 3000 \mu \mathrm{g} \text { with } 0.451 \mathrm{mg} \text { folate } \\
(24 \mathrm{~d})\end{array}$ & Bayer & Yes & Yes & No \\
\hline & Safyral (US) & $\begin{array}{l}30 / 3000 \mu \mathrm{g}+0.451 \mathrm{mg} \text { folate } \\
(21 \text { active days) }\end{array}$ & Bayer & No & Yes & No \\
\hline \multicolumn{7}{|l|}{ Biphasic } \\
\hline \multirow{3}{*}{ EE with levonorgestrel } & Seasonale (Canada, US) & $30 / 150 \mu \mathrm{g}$ & Teva & Yes & Yes & No \\
\hline & Seasonique (Canada, US) & $30 / 150 \mu \mathrm{g}+10 \mu \mathrm{g} E \mathrm{E}$ & Teva & Yes & Yes & No \\
\hline & LoSeasonique (US) & $20 / 150 \mu \mathrm{g}+0.01 \mathrm{mg}$ & Teva & No & Yes & No \\
\hline \multicolumn{7}{|l|}{ Triphasic } \\
\hline EE with desogestrel & $\begin{array}{l}\text { Linessa (Canada), } \\
\text { Cyclessa (Canada,US) }\end{array}$ & $25 / 100,25 / 125,25 / 150 \mu \mathrm{g}$ & Merck & Yes & Yes & No \\
\hline EE with norgestimate & $\begin{array}{l}\text { Ortho Tri-Cyclen Lo (US), } \\
\text { Tricyclen Lo (Canada) }\end{array}$ & $25 / 180,25 / 215,25 / 250 \mu \mathrm{g}$ & Janssen & Yes & Yes & No \\
\hline \multicolumn{7}{|l|}{4 Phases } \\
\hline EE with levonorgestrel & Quartette (US) & $20 / 150,25 / 150,30 / 150 \mu \mathrm{g}+10 \mu \mathrm{g}$ & Teva & No & Yes & No \\
\hline \multicolumn{7}{|l|}{5 Phases } \\
\hline $\begin{array}{l}\text { Estradiol valerate with } \\
\text { dienogest }\end{array}$ & $\begin{array}{l}\text { Natazia (Canada, US), } \\
\text { Qlaira (UK) }\end{array}$ & $(1 / 2 / 3 \mathrm{mg}) /(2 / 3 \mathrm{mg})$ & Bayer & Yes & Yes & Yes \\
\hline \multicolumn{7}{|l|}{ Transdermal } \\
\hline $\begin{array}{l}\text { EE with } \\
\text { 17-deacetylnorgestimate }\end{array}$ & $\begin{array}{l}\text { Ortho-Evra (Canada, US, } \\
\text { UK) }\end{array}$ & $320 / 150 \mu \mathrm{g} / \mathrm{d}$ & Janssen & Yes & Yes & Yes \\
\hline \multicolumn{7}{|c|}{ Intravaginal } \\
\hline EE with etonogestrel & $\begin{array}{l}\text { NuvaRing (Canada, US, } \\
\text { UK) }\end{array}$ & $15 / 120 \mu \mathrm{g} / \mathrm{d}$ & Merck & Yes & Yes & Yes \\
\hline \multicolumn{7}{|l|}{ Implants } \\
\hline Etonogestrel & $\begin{array}{l}\text { Implanon, Nexplanon } \\
\text { (US, UK) }\end{array}$ & $68 \mathrm{mg} / \mathrm{implant}$ & Merck & No & Yes & Yes \\
\hline \multicolumn{7}{|c|}{ Emergency contraceptives } \\
\hline \multirow[t]{2}{*}{ Levonorgestrel } & $\begin{array}{l}\text { Plan B One-Step (US), } \\
\text { Levonelle One Step (UK) }\end{array}$ & $1.5 \mathrm{mg}$ & Teva, Lupin & No & Yes & Yes \\
\hline & $\begin{array}{l}\text { Plan B (Canada, US), } \\
\text { Levonelle (UK) }\end{array}$ & $0.75 \mathrm{mg}$ & Teva & Yes & Yes & Yes \\
\hline Ulipristal acetate & ella (US), ellaOne (UK) & $30 \mathrm{mg}$ & HRA Pharma & Yes & Yes & Yes \\
\hline \multicolumn{7}{|c|}{ Intrauterine progestogen-only system } \\
\hline \multirow[t]{2}{*}{ Levonorgestrel } & Mirena (Canada, US, UK) & $52 \mathrm{mg} / \mathrm{IUD}$ & Bayer & Yes & Yes & Yes \\
\hline & $\begin{array}{l}\text { Skyla (US), Jaydess } \\
\text { (Canada, UK) }\end{array}$ & $13.5 \mathrm{mg}$ & Bayer & Yes & Yes & Yes \\
\hline
\end{tabular}


Implantable contraceptives are included by the World Health Organization on the "Who Model List of Essential Medicines." 38 Two types have been approved by both the FDA and the MHRA; none are currently approved for use in Canada. This is relevant because implants have been shown to uniquely address individual needs for a wide range of women and have a substantial positive effect on population health and the reduction of unintended pregnancy, abortion and adverse neonatal outcomes, particularly among vulnerable populations, such as teenagers, single mothers and low-income families. ${ }^{9-11,15-18,22,39-42}$ Although current contraceptive implants have not been approved, Health Canada has approved the active ingredients now used in implants, either etonogestrel or levonorgestrel, for use in other contraceptive products.

The differences in approval times between countries may reflect a range of contextual conditions. For example, before 1992, Canada and the US had similar drug approval times. ${ }^{43}$ The implementation of the Prescription Drug User Fee Act in $1992^{44}$ saw a shortening of the US drug approval times. This act allows for the collection of fees from the pharmaceutical companies and thus allowed the FDA to speed up the approval process. The requirement of a fee appeared correlated with a shorter approval time. ${ }^{45}$ In 1995 , Health Canada's Therapeutic Products Program reduced approval time from 1057 days to 650 days by processing the excess submissions. ${ }^{45}$ As of April 2016, Health Canada required manufacturers to pay a higher but variable fee, depending on the presence of a new active substance. ${ }^{46}$ The MHRA requires a much smaller fee payment for new applications of drugs containing an active substance, in the range of $5 \%-10 \%$ of the fees of Health Canada. ${ }^{47,48}$ Conversely, the FDA requires a fee more than 10 times that of Health Canada for a new drug application with clinical data. ${ }^{44}$ The large differences in fees between the 3 countries may be due to a variety of factors, including the size of the market for the product within the country.

The regulation of drug approval in the UK has a different context and process. In Europe, 2 different approval approaches are known as the Centralised Procedure and the Mutual Recognition Procedure. The Centralised Procedure involves the EMA. Drug manufacturers submit applications directly to the EMA, making their drug accessible across all EU member states. For certain drugs, such as those needed to treat AIDS, diabetes, cancer and neurodegenerative diseases, companies have to submit their applications to the EMA owing to the importance of the drugs. The second method of approval, the Mutual Recognition Procedure, allows companies to submit to a single country, such as the UK. The first country to receive an application becomes the Reference Member State and is subsequently required to prepare an assessment report for the other countries. A third way a drug may receive approval occurs when it has yet to be approved in any EU country. When this occurs, all the concerned countries may work together to set up a draft assessment report to resolve potential conflicts and expedite approval. ${ }^{49,50}$ Thus, the approval times in individual countries are influenced by different policies and procedures.

In addition to a delay in approval of contraceptives in Canada, there is a delay in application submissions by pharmaceu- tical companies to Health Canada. There may be a role for proactive leadership to facilitate or invite application submissions for contraceptives with important proven advantages to population health.

In 2004, Azzarello and Collins ${ }^{1}$ postulated that the 2002 Health Canada guideline "Guidance for Industry: Clinical Development of Steroidal Contraceptives used by Women," which includes criteria in excess of those required by regulators in the US, UK, France and Sweden, was responsible for the delay and decline in the number of applications for hormonal contraception approval in Canada. In particular, the

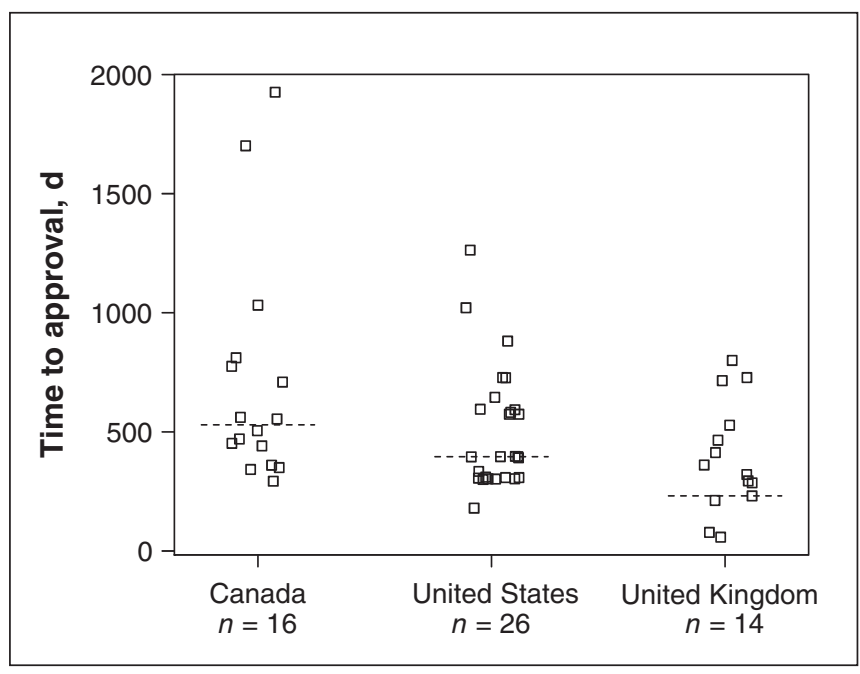

Figure 2: Distribution of time to approval for hormonal contraceptives, 2000-2015, by country. The squares indicate approval times for each drug and the dashed lines indicate the medians.

\begin{tabular}{|c|c|c|c|}
\hline \multirow[b]{2}{*}{ Contraceptive } & \multicolumn{3}{|c|}{$\begin{array}{c}\text { Approval time, } d \\
\text { (order of submission date*) }\end{array}$} \\
\hline & Canada & US & UK \\
\hline Yasmin (Canada, US, UK) & $1926(2)$ & $728(1)$ & $212(3)$ \\
\hline $\begin{array}{l}\text { Seasonale (Canada, } \\
\text { US, UK) }\end{array}$ & $561(2)$ & $396(1)$ & NA \\
\hline $\begin{array}{l}\text { Natazia (Canada, US), } \\
\text { Qlaira (UK) }\end{array}$ & $775(3)$ & $308(2)$ & $361(1)$ \\
\hline Ortho-Evra (Canada, US, UK) & 505 (3) & $334(1)$ & $528(2)$ \\
\hline NuvaRing (Canada, US, UK) & $554(2)$ & $645(1)$ & $465(3)$ \\
\hline $\begin{array}{l}\text { Implanon, Nexplanon } \\
\text { (US, UK) }\end{array}$ & NA & $1021(1)$ & $78(2)$ \\
\hline $\begin{array}{l}\text { ella (Canada, US), } \\
\text { ellaOne (UK) }\end{array}$ & $452(3)$ & $306(2)$ & $715(1)$ \\
\hline Mirena (Canada, US, UK) & 709 (2) & $310(3)$ & $58(1)$ \\
\hline $\begin{array}{l}\text { Note: } N A=\text { not available. } \\
\text { "Order of submission date is ranked b } \\
\text { contraceptive was submitted for appro } \\
\text { submitted the earliest, " } 2 \text { " the next ear }\end{array}$ & $\begin{array}{l}\text { le date wh } \\
\text { "1" repres } \\
\text { t and "3" t| }\end{array}$ & $\begin{array}{l}\text { he applicat } \\
\text { the countr } \\
\text { test. }\end{array}$ & $\begin{array}{l}\text { or a novel } \\
\text { at }\end{array}$ \\
\hline
\end{tabular}


requirement for endometrial biopsy of study participants was cited as contrasting with requirements in other jurisdictions. Health Canada continues to post the 2002 guideline on its website. ${ }^{51}$ Thus, it is possible the excess Canadian clinical trial requirements, compared with other countries, are related to the delays we report, which continue to reflect those found by Azzarello and Collins. ${ }^{1}$

\section{Limitations}

We were unable to locate information on applications that may have been submitted to Health Canada but were not approved. ${ }^{19,52}$ Thus, there is no public information on whether any application for approval of a contraceptive sub-dermal implant has been made to Health Canada, or if an application had been assessed but not approved.

Due to the lack of publicly available data on the health product regulatory agency websites or in publications, direct correspondence with the agencies was required to collect missing data from all 3 regulators. Thus, the potential for bias may be introduced through reliance on agency employees to report application and approval times. However, we consider that the details provided to our requests were approved by the agency before their response, and thus may be considered accurate.

In addition, although Canada takes longer than the US to approve novel hormonal contraceptives, it is important to note that the sample is very small and the number of tests is large so this result should be understood within these cautions. The fact that the data since 2000 have continued trends noted previously by both Azzarello and Collins ${ }^{1}$ and Shajarizadeh and colleagues $^{3}$ strengthens the suggestion of our findings.

Comprehensive data presentation by health regulatory agency websites could improve transparency and provide better public information. As we used every source we were able to identify for each portion of the data, and established triangulation between multiple sources for most data, we are confident that our data are reliable and represent all hormonal contraceptives approved during this period within Canada, the US and the UK.

\section{Conclusion}

Canadian women have access to fewer contraceptive choices and wait longer for access. These problems appear to relate to the delay in submission of applications for new contraceptives to Health Canada, and to current Canadian federal regulatory policies and procedures that require significantly more time than in the US to assess novel contraceptives. Additionally, when both novel and nonnovel application approval times are considered there is a trend to greater delay in Canada. No implantable contraceptives, a category of highly effective "set and forget" LARC methods deemed essential by the World Health Organization, have been approved for use in Canada, although the active drugs are approved in other delivery systems. Availability of a variety of hormonal contraception options, including implants, could address rates of unintended pregnancy and abortion. Canadian health systems could improve population health through addressing the regulatory barriers associated with the unmet need for contraception, including the current absence of an approved contraceptive implant method, and the prolonged novel drug approval times, in order to assist Canadians to plan and space their pregnancies.

\section{References}

1. Azzarello D, Collins J. Canadian access to hormonal contraceptive drug choices. FOGC 2004;26:489-500

2. Downing NS, Aminawing JA, Shah ND, et al. Regulatory review of novel therapeutics - comparison of three regulatory agencies. $N$ Engl $7 \mathrm{Med}$ 2012;366:2284-93.

3. Shajarizadeh A, Hollis A. Delays in the submission of new drugs in Canada. CMA7 2015;187: E47- 51 .

4. Norman WV. Induced abortion in Canada 1974-2005: trends over the first generation with legal access. Contraception 2012;85:185-91.

5. Jones RK, Kavanaugh ML. Changes in abortion rates between 2000 and 2008 and lifetime incidence of abortion. Obstet Gynecol 2011;117:1358-66.

6. Wellings $\mathrm{K}$, Jones KG, Mercer CH, et al. The prevalence of unplanned pregnancy and associated factors in Britain: findings from the third National Survey of Sexual Attitudes and Lifestyles (Natsal-3). Lancet 2013;382:1807-16.

7. Black A, Yang Q, Wu Wen S, et al. Contraceptive use among Canadian women of reproductive age: results of a national survey. 7 Obstet Gynaecol Can 2009;31:627-40.

8. Johnson S, Pion C, Jennings V. Current methods and attitudes of women towards contraception in Europe and America. Reprod Health 2013;10:7.

9. Hatcher RA, Trussel J, Nelson AL. Contraceptive technology. 20th rev ed. New York: Ardent Media; 2011.

10. Halpern V, Lopez L, Grimes DA, et al. Strategies to improve adherence and acceptability of hormonal methods for contraception. Cochrane Database Syst Rev 2011;(4):CD004317.

11. Trussell J. Contraceptive failure in the United States. Contraception 2011;83: 397-404.

12. Bahamondes L, Valeria Bahamondes M, Shulman LP. Non-contraceptive benefits of hormonal and intrauterine reversible contraceptive methods. Hum Reprod Update 2015;21:640-51.

13. Seidman DS. Non-contraceptive benefits of hormonal contraception: time for renewed awareness. Eur $\mathcal{F}$ Contracept Reprod Health Care 2011;16:407-8.

14. Grossman Barr N. Managing adverse effects of hormonal contraceptives. Am Fam Physician 2010;82:1499-506.

15. Romero L, Pazol K, Warner L, et al.; Centers for Disease Control and Prevention. Vital signs: trends in use of long-acting reversible contraception among teens aged 15-19 years seeking contraceptive services — United States, 2005-2013. MMWR Morb Mortal Wkly Rep 2015;64:363-9.

16. American College of Obstetricians and Gynecologists Committee on Gynecologic Practice; Long-Acting Reversible Contraception Working Group. ACOG Committee Opinion no. 450: increasing use of contraceptive implants and intrauterine devices to reduce unintended pregnancy. Obstet Gynecol 2009;114: 1434-8.

17. Ricketts S, Klingler G, Schwalberg R. Game change in Colorado: widespread use of long-acting reversible contraceptives and rapid decline in births among young, low-income women. Perspect Sex Reprod Health. 2014;46:125-32.

18. Biggs MA, Rocca CH, Brindis CD, et al. Did increasing use of highly effective contraception contribute to declining abortions in Iowa? Contraception. 2015;91:167-73

19. Drugs and Health Products: Drug Product Database. Ottawa: Health Canada. Available: www.hc-sc.gc.ca/dhp-mps/prodpharma/databasdon/index-eng.php (accessed 2016 Oct. 26).

20. Marnach ML, Long ME, Casey PM. Current issues in contraception. Mayo Clin Proc. 2013;88:295-9.

21. Lamvu G, Steiner MJ, Condon S, et al. Consistency between most important reasons for using contraception and current method used: the influence of health care providers. Contraception. 2006;63:399-403.

22. Wellings K, Brima N, Sadler K, et al. Stopping and switching contraceptive methods: findings from Contessa, a prospective longitudinal study of women of reproductive age in England. Contraception 2015;91:57-66.

23. Notice of Compliance search. Ottawa: Health Canada; modified 2016. Available: http://webprod5.hc-sc.gc.ca/noc-ac/index-eng.jsp (accessed 2016 Oct. 26).

24. Drugs and Health Products: Patent Register. Ottawa: Health Canada; modified 2015. Available: http://pr-rdb.hc-sc.gc.ca/pr-rdb/index-eng.jsp (accessed 2016 Oct. 26)

25. Regulatory review of pharmaceuticals, biologics, and medical devices: 2004 annual summary of performance. Ottawa: Health Canada; 2004.

26. Regulatory review of pharmaceuticals, biologics, and medical devices: 2005 annual summary of performance. Ottawa: Health Canada; 2005.

27. Health Products and Food Branch: 2006-07 performance report: a year of progress and achievement. Ottawa: Health Canada; 2008.

28. Therapeutic Products Directorate: drug submission performance annual report, fiscal year 2013-2014. Ottawa: Health Canada; 2014. 
29. Therapeutic Products Directorate: drug submission performance annual report, fiscal year 2011-2012. Ottawa: Health Canada; 2015.

30. Approved Drug Products [database]. Silver Spring (MD): US Food and Drug Administration. Available: www.accessdata.fda.gov/scripts/cder/drugsatfda/ index.cfm (accessed 2014 Nov. 30).

31. European Medicines Agency [homepage]. Available: www.ema.europa.eu/ema/ index.jsp?curl=pages/includes/medicines/medicines_landing_page.jsp\&mid $=(\mathrm{ac}-$ cessed 2015 Feb. 30)

32. Medicines and Healthcare Regulatory Agency [homepage]. Available: https:// www.gov.uk/government/organisations/medicines-and-healthcare-products -regulatory-agency (accessed 2015 Feb. 30)

33. Snow B. Drug information: a guide to current resources. 3rd ed. New York: NealSchuman Publishers; 2008.

34. Medicine information: SPCs \& PILs [summaries of product characteristics and patient information leaflets]. London (UK): Medicines and Healthcare Products Regulatory Agency. Available: www.mhra.gov.uk/spc-pil (accessed 2016 Oct. 26).

35. Public assessment reports. London (UK): Medicines and Healthcare Products Regulatory Agency. Available: www.mhra.gov.uk/public-assessment-reports (accessed 2016 Oct. 26).

36. Directory of Hormonal Contraceptives. London (UK): International Planned Parenthood Federation. Available: http://contraceptive.ippf.org/search (accessed 2014 Dec. 16)

37. Drug information handbook. 23rd ed. Hudson (OH): Lexicomp; 2014.

38. WHO model list of essential medicines: 19th list. World Health Organization; 2015. Available: www.who.int/medicines/publications/essentialmedicines/ EML_2015_FINAL_amended_NOV2015.pdf?ua=1 (accessed 2016 Oct. 26).

39. Secura GM, Madden T, McNicholas C, et al. Provision of no-cost, long-acting contraception and teenage pregnancy. N Engl 7 Med. 2014;371:1316-23.

40. Goldthwaite LM, Duca L, Johnson RK, et al. Adverse birth outcomes in Colorado: assessing the impact of a statewide initiative to prevent unintended pregnancy. Am 7 Public Health. 2015;105:e60-6.

41. Connolly A, Pietri G, Yu J, et al. Association between long-acting reversible contraceptive use, teenage pregnancy, and abortion rates in England. Int $\mathcal{f}$ Womens Health 2014;6:961-74.

42. Hathaway M, Torres L, Vollett-Krech J, et al. Increasing LARC utilization: any woman, any place, any time. Clin Obstet Gynecol. 2014;57:718-30.

43. How are drugs reviewed in Canada. Ottawa: Health Canada; modified 2015. Available: www.hc-sc.gc.ca/dhp-mps/prodpharma/activit/fs-fi/reviewfs_ examenfd-eng.php (accessed 2015 Aug. 30).

44. Prescription Drug User Fee Act. Silver Spring (MD): US Food and Drug Administration; updated 2016. Available: www.fda.gov/ForIndustry/UserFees/ PrescriptionDrugUserFee/default.htm (accessed 2016 May 14).

45. Gagnon D. Working in partnerships, drug review for the future: review of the Canadian drug approval system. Ottawa: Health and Welfare Canada; 1992:31.
46. Drugs and health products: pharmaceutical submission and application review fees. Ottawa: Health Canada; modified 2016. Available: www.hc-sc.gc.ca/dhp -mps/finance/fees-frais/pharma-eng.php (accessed 2016 June 9).

47. Current MHRA fees. Active pharmaceutical ingredients, manufacturers and importers registration fees. London (UK): Medicines and Healthcare Products Regulatory Agency. Available: https://www.gov.uk/government/publications/ mhra-fees/current-mhra-fees\#active-pharmaceutical-ingredients-manufacturers -and-importers-registration-fees (accessed 2016 June 9).

48. MHRA fees - definitions. London (UK): Medicines and Healthcare Products Regulatory Agency. Available: https://www.gov.uk/government/uploads/system/ uploads/attachment_data/file/425013/MHRA_fees_definitions.pdf (accessed on 2016 June 9).

49. Food and drugs: applications for FDA approval to market a new drug. In: Electronic code of federal regulations. Washington (DC): US Government Publishing Office; 2016. Available: www.ecfr.gov/coi-bin/text-idx?SID=5cb44c24502111026 be25253a1a298d4\&node=21:5.0.1.1.4.7.1.3\&rgn=div8 (accessed 2016 June 9).

50. Food and drugs: investigational new drug application. In: Electronic code of federal regulations. Washington (DC): US Government Publishing Office; 2016. Available: www.ecfr.gov/cgi-bin/text-idx?SID=c262a5bdfa3e4f3b1cff70 9884a3f9a2 \& node $=21: 5 \cdot 0 \cdot 1 \cdot 1 \cdot 3 \cdot 6.1 .3 \&$ rgn $=\operatorname{div} 8$ (accessed 2016 June 9).

51. Guidance for industry: clinical development of steroidal contraceptives used by women. Ottawa: Health Canada; 2002. Available: www.hc-sc.gc.ca/dhp-mps/prodpharma/ applic-demande/guide-ld/oral/contracep-eng.php (accessed 2016 Aug. 12).

52. Rawson NSB. Time required for approval of new drugs in Canada, Australia, Sweden, the United Kingdom and the United States in 1996-1998. CMAf 2000;162:501-4.

Affiliations: Faculty of Pharmaceutical Sciences (Troskie, Soon), University of British Columbia; Contraception Access Research Team (Troskie, Soon, Albert, Norman), Women's Health Research Institute; Department of Family Practice, Faculty of Medicine (Soon, Norman), University of British Columbia, Vancouver, BC

Contributors: Wendy Norman conceived the study, all of the authors contributed to study design and analysis, and Christine Troskie collected the data. Christine Troskie drafted the manuscript, which all of the authors revised. All of the authors gave final approval of the version to be published and agreed to act as guarantors of the work.

Supplemental information: For reviewer comments and the original submission of this manuscript, please see www.cmajopen.ca/content/4/4/ E654/suppl/DC1 